\title{
Complete genome sequencing and analysis of six enterovirus 71 strains with different clinical phenotypes
}

Hong-ling Wen ${ }^{1 \dagger}$, Lu-ying $\mathrm{Si}^{1+}$, Xiao-jing Yuan', Shu-bin Hao², Feng Gao ${ }^{3}$, Fu-lu Chu' ${ }^{1}$, Cheng-xi Sun ${ }^{1}$ and Zhi-yu Wang ${ }^{1 *}$

\begin{abstract}
Background: Hand, foot and mouth diseases (HFMD) caused by enterovirus 71(EV71) presents a broad spectrum of clinical manifestations ranging from mild febrile disease to fatal neurolocal disease. However, the mechanism of virulence is unknown.

Methods: We isolated 6 strains of EV71 from HFMD patients with or without neurological symptoms, and sequenced the whole genomes of the viruses to reveal the virulence factors of EV71.

Results: Phylogenetic tree based on VP1 region showed that all six strains clustered into C4a of C4 sub-genotype. In the complete polypeptide, 298 positions were found to be variable in all strains, and three of these positions $\left(\mathrm{Val}^{\mathrm{P} 814} / \mathrm{Il}^{\mathrm{P} 814}\right.$ in $\mathrm{VP1}, \mathrm{Val}^{\mathrm{P} 1148} / \mathrm{Il}^{\mathrm{P} 1148}$ in $3 \mathrm{~A}$ and $\mathrm{Ala}{ }^{\mathrm{P} 1728} / \mathrm{Cys}^{\mathrm{P} 1728} \mathrm{Nal}{ }^{\mathrm{P} 1728}$ in $3 \mathrm{C}$ ) were conserved among the strains with neurovirulence, but variable in strains without neurovirulence. In the $5^{\prime}$-UTR region, it showed that the first 10 nucleotides were mostly conserved, however from the 11th nucleotide, nucleotide insertions and deletions were quite common. The secondary structure prediction of $5^{\prime}$-UTR sequences showed that two of three strains without neurovirulence (SDLY11 and SDLY48) were almost the same, and all strains with neurovirulence (SDLY96, SDLY107 and SDLY153) were different from each other. SDLY107 (a fatal strain) was found different from other strains on four positions $\left(C^{P 241} / T^{P 241}, A^{P 571} / T^{P 571}, C^{P 579} / T^{P 579}\right.$ in $5^{\prime}-U T R$ and $T^{P 7335} / C^{P 7335}$ in $\left.3^{\prime}-U T R\right)$. Conclusions: The three positions ( $\mathrm{Val} \mathrm{P}^{\mathrm{P} 14} / \mathrm{Il}^{\mathrm{P} 814}$ in $\mathrm{VP1}, \mathrm{Val} \mathrm{l}^{\mathrm{P} 1148} / \mathrm{Il}^{\mathrm{P} 1148}$ in $3 \mathrm{~A}$ and $\mathrm{Ala}{ }^{\mathrm{P} 1728} / \mathrm{Cys}^{\mathrm{P} 1728} \mathrm{Nal}^{\mathrm{P} 1728}$ in $\left.3 \mathrm{C}\right)$, were different between two phenotypes. These suggested that the three positions might be potential virulent positions. And the three varied positions were also found to be conserved in strains with neurovirulence, and variable in strains without neurovirulence. These might reveal that the conservation of two of the three positions or the three together were specific for the strains with neurovirulence. Varation of secondary structure of $5^{\prime}$-UTR, might be correlated to the changes of viral virulence. SDLY107 (a fatal strain) was found different from other strains on four positions, these positions might be related with death.
\end{abstract}

Keywords: Enterovirus 71, Virulent determinant, Hand, foot and mouth disease

\footnotetext{
* Correspondence: zhiyu.wang@sdu.edu.cn

${ }^{\dagger}$ Equal contributors

${ }^{1}$ The Key Laboratory of experimental teratology of Ministry of Education, Department of Virology, School of Public Health, Shandong University, Jinan, Shandong 250012, People's Republic of China

Full list of author information is available at the end of the article
} 


\section{Background}

Enterovirus 71 (EV71) belongs to the Enterovirus genus of the family Picornaviridae. It is one of the pathogens that are associated with hand, foot and mouth disease (HFMD). In most cases, EV71 infections are generally mild. However, this virus has also been implicated to cause severe neurological manifestations including aseptic meningitis, polio-like paresis and possibly fatal encephalitis [1].

Since 1969, when EV71 was first isolated in California, USA [2], EV71 associated outbreaks have been reported worldwide [3-10]. In recent years, it has gained more attention as there is an upward trend in the prevalence of EV71 in Asia [11]. EV71 infection is a serious threat to the health of infants and young children; therefore, it is necessary to understand the mechanism of central nervous system involvement. Zheng et al. reported nucleotide differences in $5^{\prime}$-UTR between strains isolated from patients with and without neurological symptom, and proposed that such variation may be correlated with different clinical presentations [12]. Shih-Cheng Chang reported that a significant amino acid change was observed in more than one of high virulent strains [13]. Melchers et al. suggested that point mutations in $3^{\prime}$ UTR can result in a lethal phenotype [14]. All these points were located in different regions of the genome, therefore, it is necessary to search for potential points associated with neurovirulence in complete genome.

\section{Results}

\section{Virus identification and segmented amplification}

All the six strains were proved to be EV71 by RT-PCR (Figure 1), and were amplified with the nine pairs of overlapping primes (Figure 2).

\section{Sequence analysis of the genomes}

The sequences of the six strains were desposited in GenBank (GenBank accession number JX244182, JX244183, JX244184, JX244185, JX244186, JX244187). The genomes of strains SDLY11, SDLY48, SDLY96 and SDLY107 were all 7405 bp in length, whereas strains SDLY1 and SDLY153 were 7408 bp in length. All six strains had one ORF which encoded a polypeptide of 2193 amino acids.

Pair-wise nucleotide and amino acid sequence comparisons showed that the genetic variation among the six strains was limited. The nucleotide homology of the genomes was $95.5 \% \sim 99.7 \%$. The amino acid homology of the polyproteins was $98.5 \% \sim 99.5 \%$. The nucleotide homology of $5^{\prime}$-UTR and $3^{\prime}$-UTR were $97.2 \% \sim 99.6 \%$ and $95.3 \sim 100.0 \%$, respectively. They shared $77.5 \%-99.0 \%$ nucleotide homology of the genomes with reference strains, and $98.6 \%$ to $89.6 \%$ at the amino acid level (Table 1).

Phylogenetic analysis of the six strains and reference strains based on the nucleotide sequences of the complete

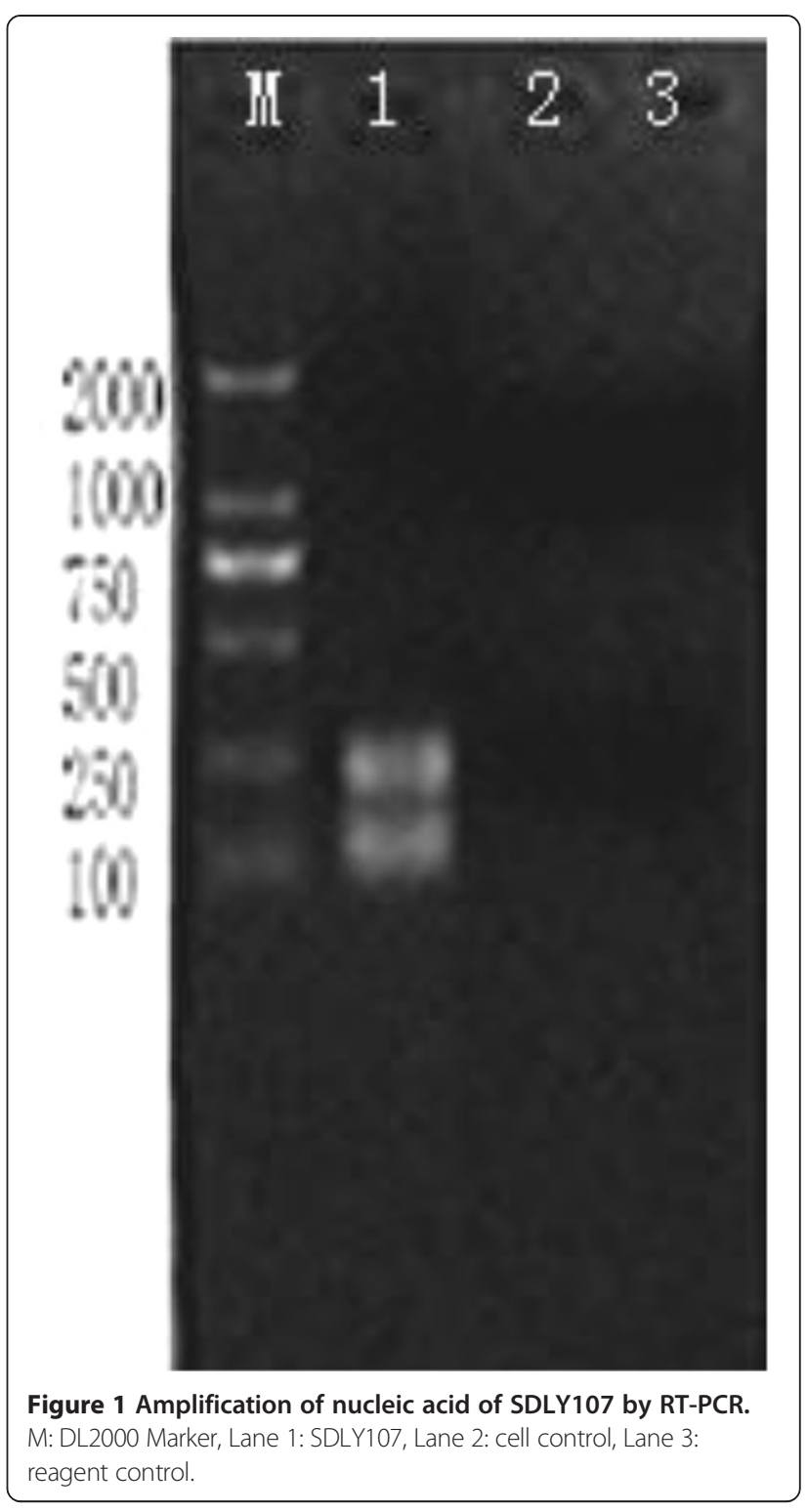

VP1 region showed that all the six strains clustered in the C4a of C4 sub-genotype (Figure 3).

\section{Analysis of polyprotein}

The polyprotein consists in three regions [15]: P1 containing capsid proteins (VP $\sim \mathrm{VP} 4), \mathrm{P} 2$ and $\mathrm{P} 3$ containing non-structural proteins $(2 \mathrm{~A}, 2 \mathrm{~B}, 2 \mathrm{C}, 3 \mathrm{~A}, 3 \mathrm{~B}, 3 \mathrm{C}$ and 3D) which are crucial for virus replication.

The complete genome sequence of 58 strains of EV71 were available in GenBank, but only 25 strains had information of clinical symptoms of the patients. 13 of the 25 strains isolated from patients with neurological symptom, and 12 of the strains were isolated from patients without neurological symptom. As we aimed to correlated sequences of defined clinical symptoms, we only 


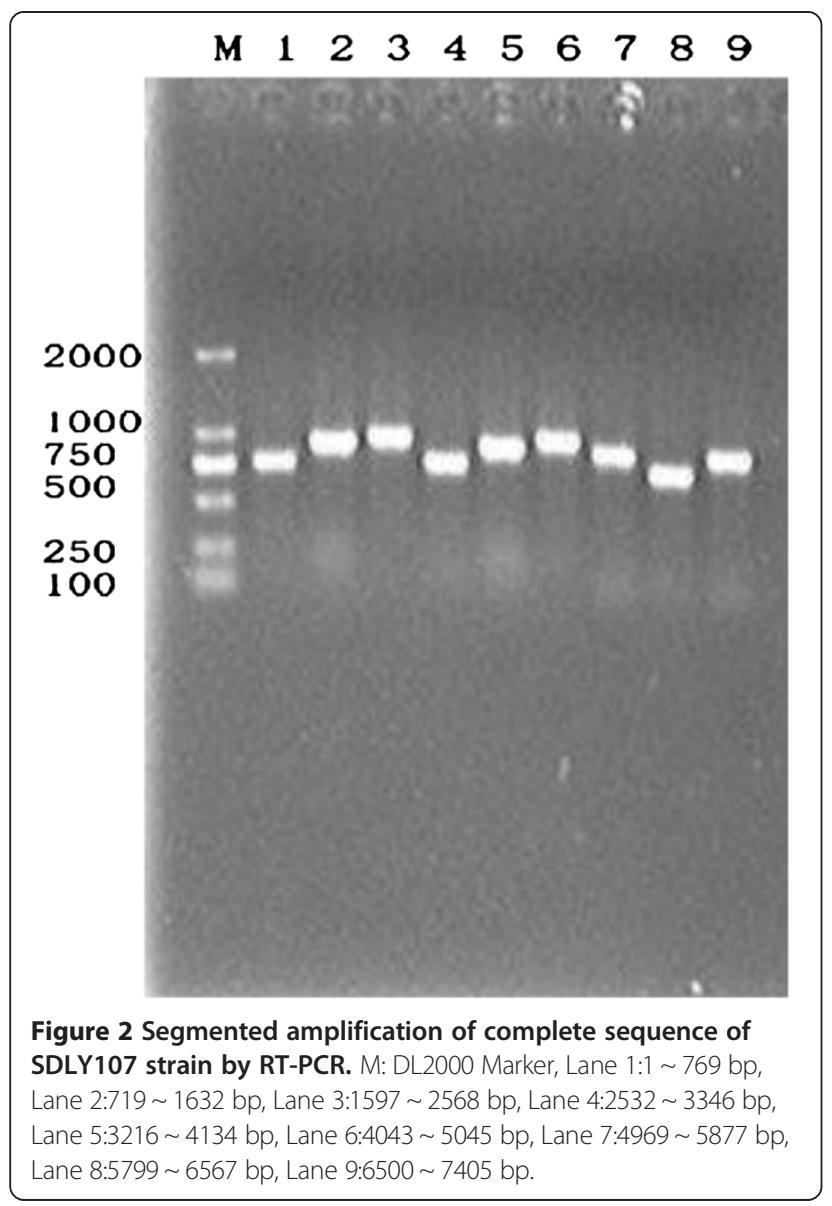

analyzed the 25 genomes of EV71 strains from GenBank that had description of clinical symptoms and the 6 strains sequenced in this study (Table 2). In the complete polyprotein, 298 positions were found to be variable and three of these positions were statistical significant (Table 3). The three points were $\mathrm{Val}^{\mathrm{P} 814} / \mathrm{Ile}^{\mathrm{P814}}$ (Fisher's Exact Test, $P=0.018, \mathrm{a}=0.05$ ), $\mathrm{Val}^{\mathrm{P} 1148} / \mathrm{Ile}^{\mathrm{P} 1148}$ (Fisher's Exact Test, $P=0.043, \mathrm{a}=0.05$ ) and Ala P1728, Cys ${ }^{\mathrm{P} 1728} / \mathrm{Val}^{\mathrm{P} 1728}$ (Fisher's Exact Test, $P=0.018$, $\mathrm{a}=0.05)$.

\section{Analysis of 5'-UTR}

$5^{\prime}$-UTR sequences of 31 strains were aligned. It showed that the first 10 nucleotides were mostly conserved, however from the 11th nucleotide, nucleotide insertions and deletions were quite common. No position was found statistical significantly different between strains with and without neurological symptom. Whereas SDLY107 (a fatal strain) was found different from other strains on three positions $\left(\mathrm{C}^{\mathrm{P} 241} / \mathrm{T}^{\mathrm{P} 241}, \mathrm{~A}^{\mathrm{P} 571} / \mathrm{T}^{\mathrm{P} 571}\right.$, $\left.\mathrm{C}^{\mathrm{P} 579} / \mathrm{T}^{\mathrm{P} 579}\right)$, suggesting that these positions might be related to death.

$5^{\prime}$-UTR sequences of 6 strains isolated in our study were aligned by BioEdit 7.09 software (Figure 4), and no significantly difference was found.

Phylogenetic analysis of 31 strains based on the nucleotide sequences of $5^{\prime}$-UTR showed no definite regularity of these strains, revealing that there was no distinction on evolution between strains with different symptoms (Figure 5).

The 5'-UTR of EV71 could be divided into two regions: the $5^{\prime}$ terminal cloverleaf and the IRES element [16]. IRES initiated genome translation by a cap-independent mechanism mediated [17]. IRES includes five stem loop (domain $\mathrm{I} \sim \mathrm{V}$ ), all of these five domains are essential to viral RNA replication and translation. The secondary structure prediction of the complete $5^{\prime}$-UTR sequences showed that two of three strains from patents without neurological symptom (SDLY11 and SDLY48) were almost the same, and all strains with neurovirulence (SDLY96, SDLY107 and SDLY153) were different from each other (Figure 6). In IRES element, domain III and II were relatively conservative regions, however, domainI, IV and V were marked variation. This information suggested that variety of secondary structure of $5^{\prime}$-UTR, especially domainI,IV and $\mathrm{V}$ might influence virulence.

\section{Analysis of $3^{\prime}$-UTR}

The $3^{\prime}$-UTR of EV71 was a highly conserved region and point mutations in the $3^{\prime}$-UTR could result in a lethal phenotype [14]. Alignment of $3^{\prime}$-UTR sequences of 31

Table 1 The nucleotide and amino acid homology of the six strains with reference strains(nucleotide/amino acid)

\begin{tabular}{lllllll}
\hline & SDLY1 & SDLY11 & SDLY48 & SDLY96 & SDLY107 & SDLY153 \\
\hline U22521(A) & $80.1 / 95.1$ & $79.9 / 95.1$ & $79.9 / 95.2$ & $79.9 / 95.0$ & $79.9 / 95.0$ & $79.9 / 94.5$ \\
ETU22522(B) & $81.9 / 95.9$ & $81.9 / 95.8$ & $81.9 / 95.9$ & $81.9 / 95.8$ & $82.0 / 95.7$ & $81.7 / 95.2$ \\
DQ341361(C1) & $82.3 / 96.3$ & $82.2 / 96.2$ & $82.5 / 96.4$ & $82.3 / 96.2$ & $82.3 / 96.2$ & $82.1 / 95.6$ \\
AF119795(C2) & $81.8 / 93.0$ & $81.4 / 93.0$ & $81.9 / 93.0$ & $81.6 / 93.0$ & $81.3 / 93.0$ & $81.3 / 92.6$ \\
DQ341356(C3) & $81.8 / 96.2$ & $81.4 / 96.2$ & $81.9 / 96.2$ & $81.6 / 96.2$ & $81.3 / 96.2$ & $81.3 / 95.6$ \\
EU703813(C4a) & $97.2 / 99.2$ & $98.9 / 99.6$ & $96.4 / 99.1$ & $99.0 / 99.6$ & $98.6 / 99.7$ & $98.4 / 99.1$ \\
AF302996(C4b) & $91.3 / 95.9$ & $91.0 / 95.9$ & $91.4 / 95.8$ & $91.0 / 95.9$ & $90.8 / 95.8$ & $90.8 / 95.2$ \\
EU527983(C5) & $82.1 / 96.4$ & $82.0 / 96.4$ & $82.3 / 96.3$ & $82.1 / 96.4$ & $82.1 / 96.5$ & $82.1 / 95.9$ \\
U05876(CA16) & $77.9 / 90.3$ & $77.6 / 90.2$ & $77.7 / 90.2$ & $77.7 / 90.2$ & $77.9 / 90.2$ & $77.5 / 89.6$ \\
\hline
\end{tabular}




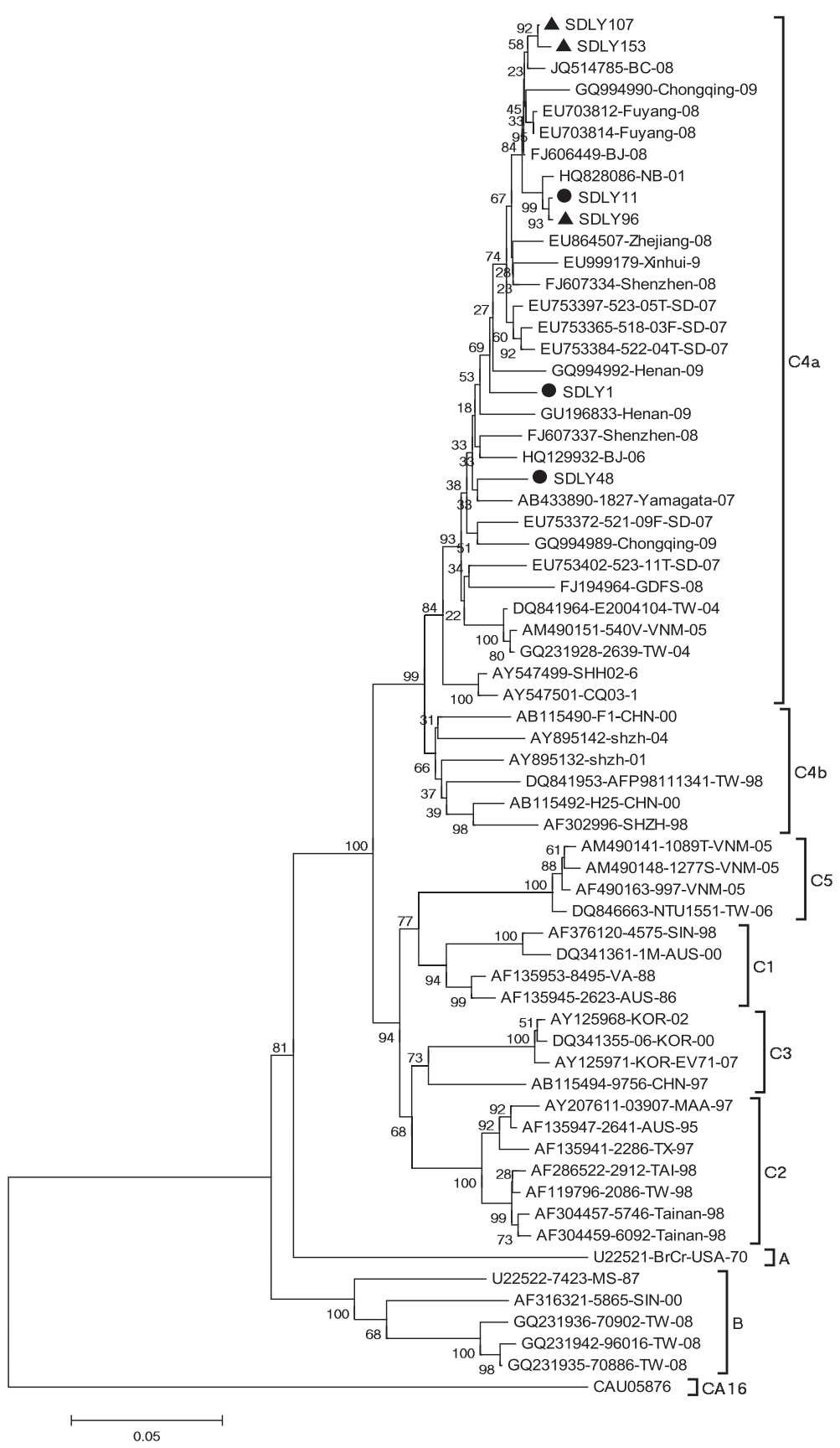

Figure 3 Phylogenetic tree hylogenetic analysis based on EV71 VP1 nucleotide sequences (891 bp). • strains isolated from patients without neurovirulence in this study, $\mathbf{\Delta}$ strains isolated from patients with neurological symptom in this study. The phylogenetic tree was drawn using the neighbor joining method. Bootstrap values are shown as percentages derived from 1000 samplings and the scale reflects the number of nucleotide substitution per site along the branches.

strains by BioEdit 7.09 software did not reveal significant position associated with virulence. However, SDLY107 (a fatal strain) was found different from other strains on position $\mathrm{T}^{\mathrm{P} 7335} / \mathrm{C}^{\mathrm{P} 7335}$, suggesting that this position might be correlated to death.

Phylogenetic analysis of 31 strains based on the nucleotide sequences of 3 -UTR (Figure 7) showed strains with different symptoms were mixed up, suggesting that there was no distinction on evolution between strains with or without neurological symptoms.

The secondary structure prediction of the complete 3 -UTR sequences showed that except strain SDLY48, the other five strains were almost the same (Figure 8). 
Table $\mathbf{2}$ Complete genome sequences of $\mathbf{3 1}$ strain used in this study

\begin{tabular}{llll}
\hline Strains with neurovirulence & & \multicolumn{2}{l}{ Strains without neurovirulence } \\
\cline { 2 - 3 } GenBank No. & Source & GenBank No. & Source \\
\hline U22522 & GenBank & EU753384 & GenBank \\
AF316321 & GenBank & HQ129932 & GenBank \\
JQ514785 & GenBank & AF304459 & GenBank \\
EU753365 & GenBank & GQ994989 & GenBank \\
GQ231942 & GenBank & FJ607334 & GenBank \\
HQ828086 & GenBank & GQ231936 & GenBank \\
GU196833 & GenBank & AF119796 & GenBank \\
EU753397 & GenBank & AF304457 & GenBank \\
GQ994992 & GenBank & GQ231935 & GenBank \\
GQ231928 & GenBank & GQ994990 & GenBank \\
EU703814 & GenBank & FJ606449 & GenBank \\
FJ607337 & GenBank & DQ341361 & Isolated in this study \\
EU703812 & GenBank & SDLY1 & Isolated in this study \\
SDLY96 & Isolated in this study & SDLY11 & Isolated in this study \\
SDLY107 & Isolated in this study & SDLY48 & \\
SDLY153 & Isolated in this study & &
\end{tabular}

\section{Discussion}

EV71 is one of the most virulent enteroviruses and can cause mortality in children [1]. Defining virulent positions on molecular level is considered as one of the most important aspects of disease prevention. In our study, complete genomes of six EV71 strains with different clinical phenotypes were sequenced and analyzed. Together with other strains isolated in Shandong in recent years, the six strains clustered into $\mathrm{C} 4 \mathrm{a}$ of $\mathrm{C} 4$ subgenotype [18].

At present, molecular neurovirulence determinant of EV71 remains unclear, though virulence factors of other enteroviruses have been reported. Nucleotide 480, 481 and 472 on $5^{\prime}$-UTR of poliovirus were identified as neurovirulence determinants of poliovirus [19-21]. Minetaro et al. reported that mutation of the EV71 standard strain $\mathrm{BrCr}$ in $5^{\prime}$-UTR showed attenuated neurovirulence in the cynomolgus monkey model [22]. In this study, insertions and deletions were frequently found in $5^{\prime}$-UTR region. Two of three EV71 strains
(SDLY11 and SDLY48) from patients without neurovirulence had almost the same secondary structure of $5^{\prime}$ UTR, and all strains with neurovirulence (SDLY96, SDLY107 and SDLY153) were different from each another. In IRES element, domain III and II were relatively conserved regions, however, domainI, IV and V are very variable. These suggest that variation of the secondary structure of the $5^{\prime}$-UTR, especially domainI, IV and V might be correlated to the virulence. When aligned the strain isolated from a fatal patient (SDLY107) with other five strains, three position of $5^{\prime}-\mathrm{UTR}\left(\mathrm{C}^{\mathrm{P} 241} / \mathrm{T}^{\mathrm{P} 241}\right.$, $\left.\mathrm{A}^{\mathrm{P} 571} / \mathrm{T}^{\mathrm{P} 571}, \mathrm{C}^{\mathrm{P} 579} / \mathrm{T}^{\mathrm{P} 579}\right)$ might be related to the virulence.Li et al. reported that four amino acids (Gly ${ }^{\mathrm{P} 710}$ / $\mathrm{Gln}^{\mathrm{P} 710} / \mathrm{Arg}^{\mathrm{P} 710}$ and $\mathrm{Glu}^{\mathrm{P} 729}$ ) in the DE and EF loop of $\mathrm{VP1}$, one $\left(\mathrm{Lys}^{\mathrm{P} 930}\right)$ in the surface of protease $2 \mathrm{~A}$ were potentially associated with EV71 virulence [23]. In our study, three positions, $\mathrm{Val}^{\mathrm{P} 814} / \mathrm{Ile}^{\mathrm{P} 814}$ in $\mathrm{VP} 1, \mathrm{Val}^{\mathrm{P} 1148}$ / Ile $^{\mathrm{P} 1148}$ in $3 \mathrm{~A}$ and Ala ${ }^{\mathrm{P} 1728} /$ Cys $^{\mathrm{P} 1728} / \mathrm{Val}^{\mathrm{P} 1728}$ in 3C, were different between two phenotypes. These results suggest that three positions are potential virulent positions.

Table 3 Significant positions of polyprotein of 31 strains

\begin{tabular}{llll}
\hline Region & Position & Amino acid & Strains without neurovirulence \\
\cline { 3 - 4 } & & Strains with neurovirulence & Val/lle(10/5) \\
\hline VP1 & 814 & Val/lle(16/0)* & Val/lle(11/4) \\
3A & 1148 & Val/lle(16/0) & $\mathrm{Ala} / \mathrm{Cys} / \mathrm{Nal}(10 / 1 / 4)$ \\
$3 C$ & 1728 & Ala/Cys/Nal $(16 / 0 / 0)$ & \\
\hline
\end{tabular}

*Val/Ile(16/0): in all 16 strains with neurovirulence, 16 of them were Val ${ }^{\mathrm{P} 814}$ and none of them was $\| \mathrm{e}^{\mathrm{P} 814}$ 


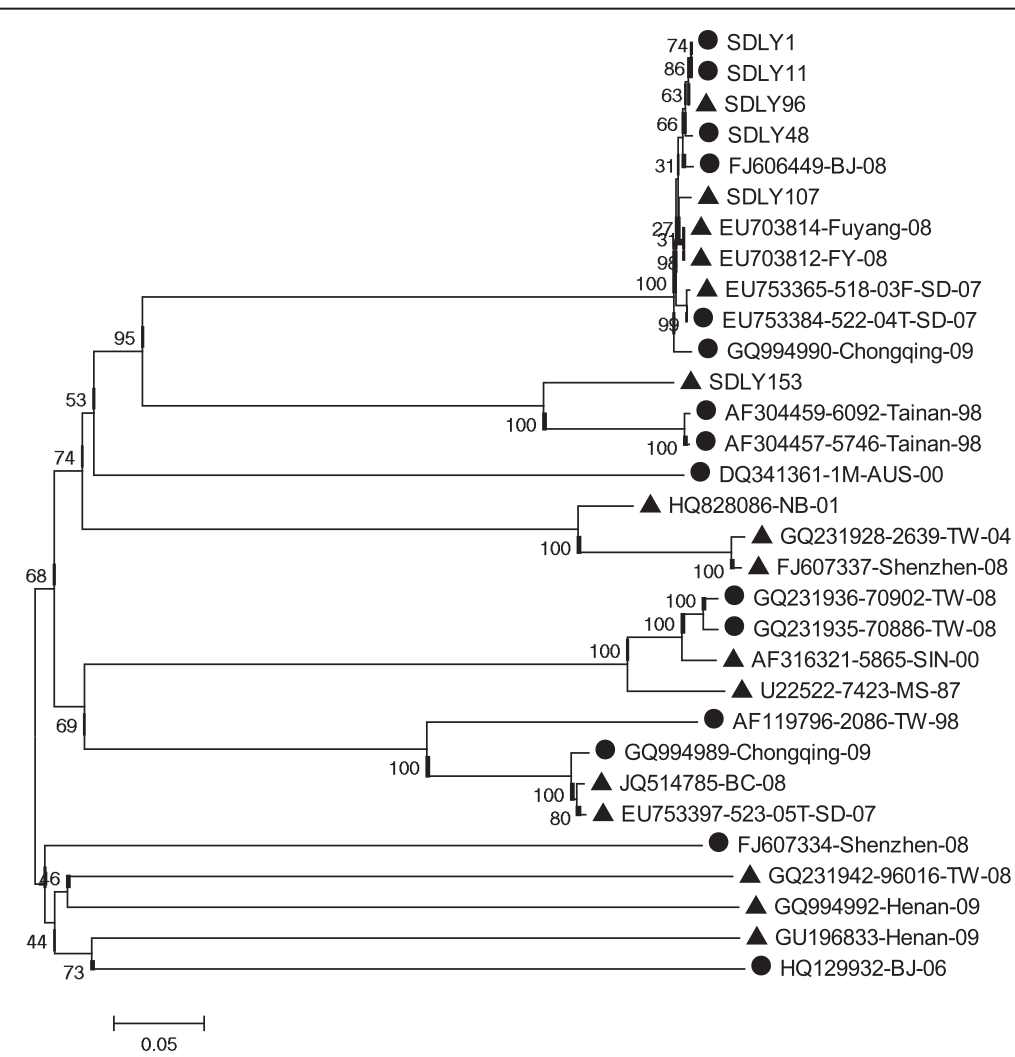

Figure 5 Phylogenetic tree hylogenetic analysis based on $\mathbf{5}^{\prime}$-UTR nucleotide sequences. $\bullet$ strains without neurovirulence, $\boldsymbol{\Delta}$ strains with neurological symptom. The phylogenetic tree was drawn using the neighbor joining method. Bootstrap values are shown as percentages derived from 1000 samplings and the scale reflects the number of nucleotide substitution per site along the branches. 


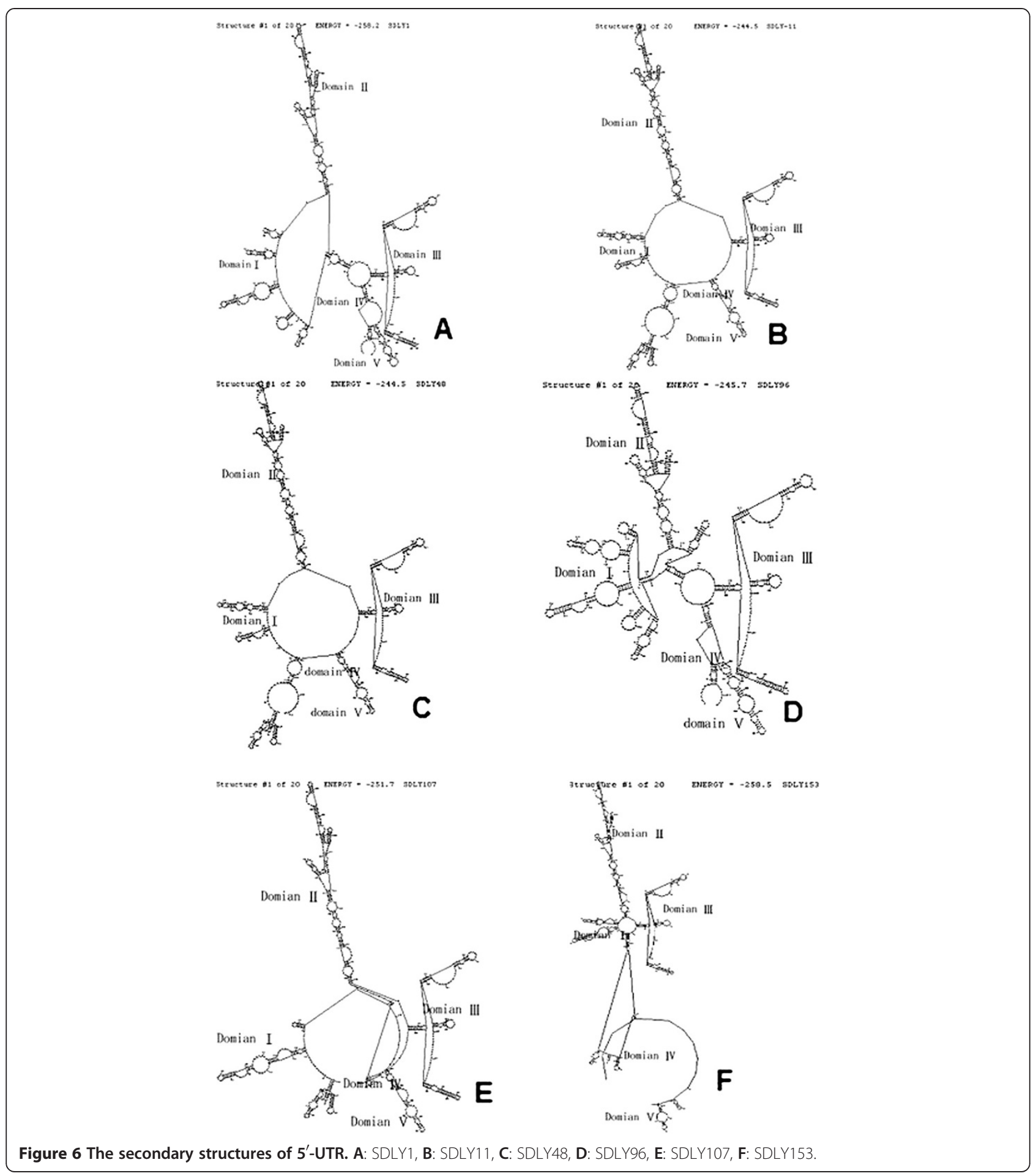

The position 814 locates in C-terminal part of the VP1 protein which locates on the surface of the virus, mediates the initiation of infection by binding to receptors on the host membrane [24]. C-terminal part of the VP1 protein were supposed to be capable of eliciting neutralizing antibodies against EV71 [25].
Variations in VP1 region may influence the ability of the virus binding to host cell and eliciting neutralizing antibodies. Protein 3A plays a role in inhibiting cellular protein secretion and mediating presentation of membrane proteins during viral infection. Variations in 3A region may affect the process of viral infection. Protein 


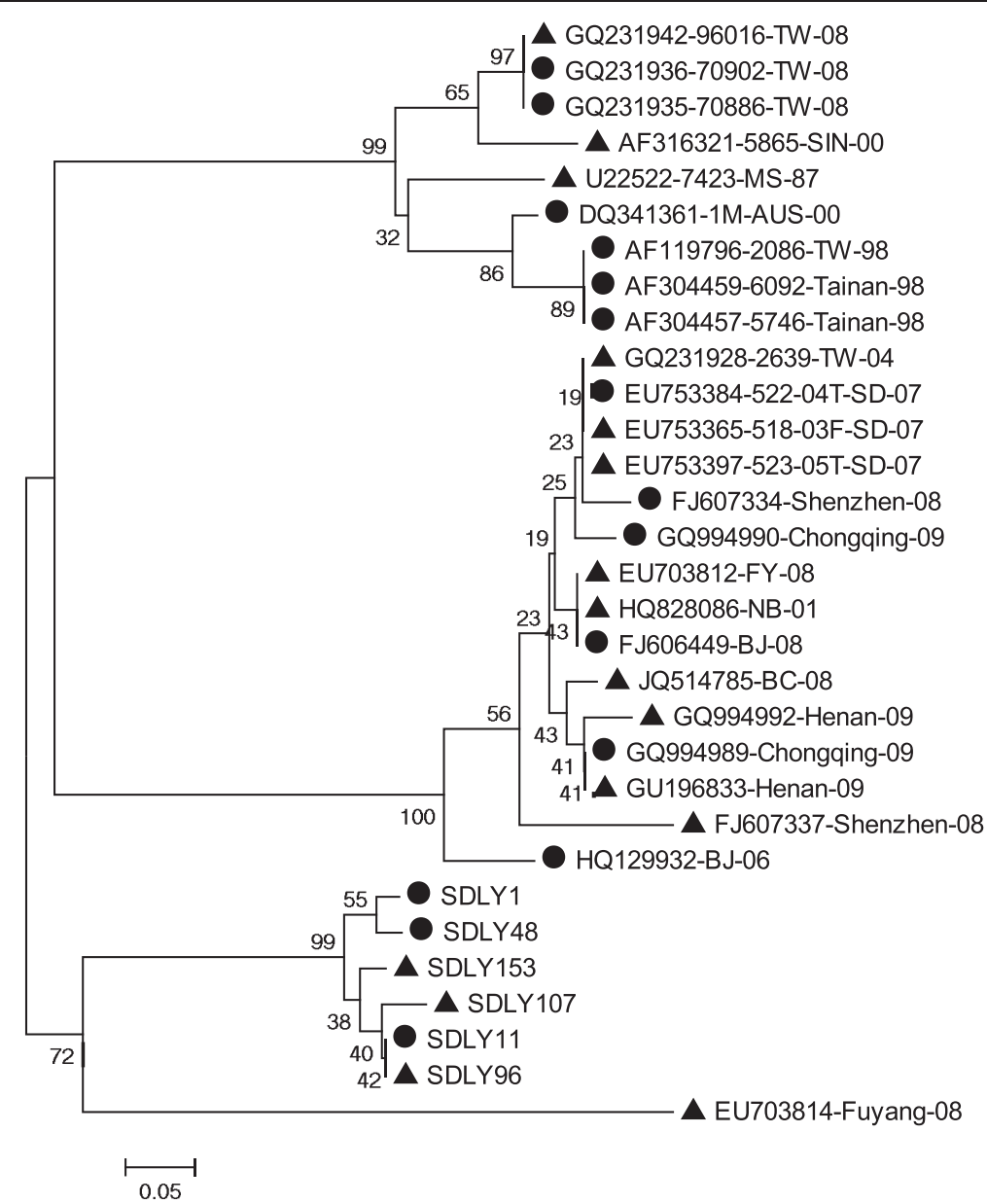

Figure 7 Phylogenetic tree hylogenetic analysis based on $3^{\prime}$-UTR nucleotide sequences. • strains without neurovirulence, $\boldsymbol{\Delta}$ strains with neurological symptom. The phylogenetic tree was drawn using the neighbor joining method. Bootstrap values are shown as percentages derived from 1000 samplings and the scale reflects the number of nucleotide substitution per site along the branches.

3C can cleave numerous factors and regulators that are associated with cellular DNA-dependant RNA polymerase I, II and III, and may be involved in the virusinduced blockage of host transcription. Variations in $3 \mathrm{C}$ region may affect activity of RNA polymerase and host cellular transcription. The three positions were conserved in strains with neurovirulence, and variable in strains without neurovirulence. These also reveales that the conservation of two of the three positions or the three together maybe specific for the strains with neurovirulence.

The 3'-UTR is a highly conserved domain and mutations in the $3^{\prime}$-UTR may cause change of phenotype. However, in our study, analysis of nucleotides of $3^{\prime}$-UTR showed no virulence associated nucleotides.

To test our aforementioned findings, site-directed mutagenesis need to be performed on these positions in the future study, and infectious cDNA clones with different potential virulent positions need to be constructed and evaluated at ex vivo and in vitro.

\section{Methods}

\section{Cells and viruses}

EV71 strains SDLY1, SDLY11, SDLY48, and SDLY96 were isolated from stool samples of four patients without neurovirulence. SDLY107, SDLY153 were isolated from anal swabs samples of two patients. Among these strains, SDLY1, SDLY11 and SDLY48 were isolated from patients with mild symptoms. SDLY96 and SDLY153 were isolated from patients with neurological symptom, and SDLY107 was isolated from a fatal patient. All six patients were from Linyi City, Shandong Province, China. Human rhabdomyosarcoma (RD) cells were maintained in DMEM supplemented with $10 \%$ FBS. Viruses were propagated on $\mathrm{RD}$ cells to increase the titer for use in subsequent assays.

\section{RNA extraction and virus identification}

Total virus RNAs were extracted from EV71-infected cell culture supernatants using a RNA extraction kit (OMEGA) following the manufacture's instructions. Virus 


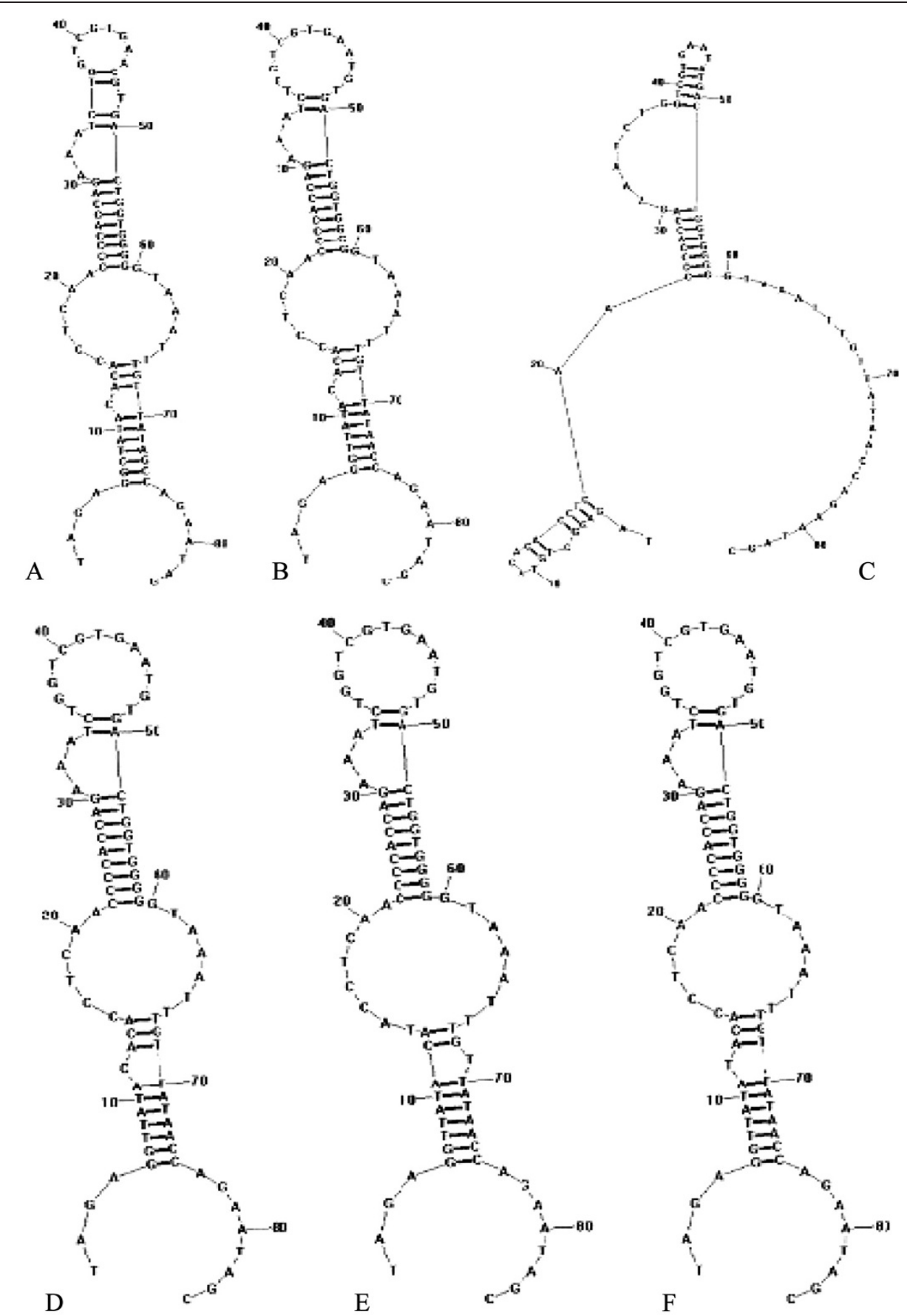

Figure 8 The secondary structures of 3'-UTR. A: SDLY1, B: SDLY11, C: SDLY48, D: SDLY96, E: SDLY107, F: SDLY153. 
Table 4 Primers used for amplifying the genome

\begin{tabular}{|c|c|c|c|}
\hline NO. & Name of primer & Sequence & Amplification(bp) \\
\hline \multirow[t]{2}{*}{1} & $\mathrm{P} 1+$ & TTAAAACAGCCTGTGGGTTGCACC & $769 \mathrm{bp}$ \\
\hline & P769- & GTGTAGACACTTGCGAACC & \\
\hline \multirow[t]{2}{*}{2} & P719+ & CTTGACCCTTAACACAGCTA & $914 \mathrm{bp}$ \\
\hline & P1632- & GCTCCTTGGTCGTAGTCTAG & \\
\hline \multirow[t]{2}{*}{3} & P1597+ & GTGCCTATTAGCCCACTAGAC & $973 \mathrm{bp}$ \\
\hline & P2568- & ACCTTGCCTGTATCCAGTCGA & \\
\hline \multirow[t]{2}{*}{4} & P2532+ & ACAGGTGAGCAGTCATCGACT & $815 \mathrm{bp}$ \\
\hline & P3346- & CTGTTGTCCAAATTTCCCAAGA & \\
\hline \multirow[t]{2}{*}{5} & P3216+ & GTGGATACCTCGCCCGATGC & $919 \mathrm{bp}$ \\
\hline & P4134- & CACTCTAACCCCTTAGCGGCGT & \\
\hline \multirow[t]{2}{*}{6} & P4043+ & CCATCTTAGGTATCCCTATCGC & $1003 \mathrm{bp}$ \\
\hline & P5045- & TTGTGTTGCCAATGGCGGACC & \\
\hline \multirow[t]{2}{*}{7} & P4969+ & GTCAGATACAGTGTGGATACG & $909 \mathrm{bp}$ \\
\hline & P5877- & CCACCAATGTGAATACCGACAA & \\
\hline \multirow[t]{2}{*}{8} & P5799+ & CAACTTTCCTACTAAAGCAGGAC & $769 \mathrm{bp}$ \\
\hline & P6567- & CCCACGGCTGATCCAGTTATCG & \\
\hline \multirow[t]{2}{*}{9} & P6500+ & TGGCTTTCGGACATTTGTATGA & $906 \mathrm{bp}$ \\
\hline & P7405- & GCTATTCTGGTTATAACAAATTTACC & \\
\hline
\end{tabular}

types were identified by One-Step RT-PCR described previously [26].

\section{Segmented amplification of the complete genomes}

Nine overlapping clones covering the whole viral genome were obtained by RT-PCR (QIAGEN, OneStep RT-PCR Kit). RT-PCR amplifications were carried out with the primers in Table 4. RT-PCR products were purified using Gel Extraction Mini Kit (OMEGA) and were cloned to the pMD19-T plasmid (TaKaRa). The recombinant vectors were transformed into competent $E$. coli DH5 $\alpha$. Positive clones were sequenced by Biosune Biotechnology Co. Ltd.

\section{Sequences analysis}

The nucleotide sequences of six complete genomes and the derived amino acid sequences were analyzed by BioEdit 7.09 software. The genotype and subgenotype were determined by comparing sequences with reference strains from GenBank. The secondary structures of $5^{\prime}$ UTR and $3^{\prime}$-UTR were predicted by RNA structure 4.0 software. The phylogenetic tree was constructed using MEGA 4 software based on the nucleotide sequences of the complete VP1 region.

\section{Ethics statement}

This study was approved by the ethical committees of School of Public Health, Shandong University, Jinan, Shandong 250012, China (permit number 20080301).
Written consents were obtained from all children's parents involved in the study.

\section{Abbreviations}

EV71: Enterovirus 71; HFMD: Hand, foot and mouth diseases; RT-PCR: Reverse transcription-polymerase chain reaction; ORF: Open reading frame; IRES: Internal ribosome entry site; DMEM: Dulbecco's modified Eagle's medium; FBS: Supplemented with 10\% fetal bovine serum.

\section{Competing interests}

The authors declare that they have no competing interests.

\section{Authors' contributions}

HLW, ZYW and SBH conceived the study and designed the experiments. LYS, XJY, FLC, CXS performed the experiments. HLW and LYS analyzed the data and wrote the manuscript. FG contributed in sample collection. All authors read and approved the final manuscript.

\section{Acknowledgements}

The research is supported by National Natural Science Foundation of China (30901265); Natural Science Foundation of Shandong Province (ZR2010CO030); Innovation Foundation of Young Talent, School of Public Health, Shandong University(GGWS200801). We thank Shandong medical equipment quality supervision and inspection center, Shandong Linyi City people's hospital for support to conduct this study.

\section{Author details}

${ }^{1}$ The Key Laboratory of experimental teratology of Ministry of Education, Department of Virology, School of Public Health, Shandong University, Jinan, Shandong 250012, People's Republic of China. ${ }^{2}$ Shandong Medical Equipment Quality Supervision And Inspection Center, Jinan, Shandong 250012, People's Republic of China. ${ }^{3}$ Linyi People's Hospital, Linyi

Shandong276000, People's Republic of China.

Received: 14 June 2012 Accepted: 2 April 2013

Published: 11 April 2013 


\section{References}

1. Hagiwara A, Yoneyama T, Takami S, Hashimoto I: Genetic and phenotypic characteristics of enterovirus 71 isolates from patients with encephalitis and with hand, foot and mouth disease. Arch Virol 1984, 79(3-4):273-283.

2. Blomberg J, Lycke E, Ahlfors K, Johnsson T, Wolontis S, von Zeipel G: New enterovirus type associated with epidemic of aseptic meningitis and or hand, foot, and mouth disease. Lancet 1974, 2(7872):112.

3. Chumakov M, Voroshilova M, Shindarov L, Shindarov L, Lavrova I, et al: Enterovirus 71 isolated from cases of epidemic poliomyelitis-like disease in Bulgaria. Arch Virol 1979, 60(3-4):329-340.

4. Ishimaru Y, Nakano S, Yamaoka K, Takami S: Outbreaks of hand, foot, and mouth disease by enterovirus 71. High incidence of complication disorders of central nervous system. Arch Dis Child 1980, 55(8):583-588.

5. Lan YC, Lin TH, Tsai JD, Yang YC, Peng CT, et al: Molecular epidemiology of the 2005 enterovirus 71 outbreak in central Taiwan. Scand J Infect Dis 2011, 43(5):345-349.

6. Kim KH: Enterovirus 71 infection: An experience in Korea 2009. Korean J Pediatr 2010, 53(5):616-622.

7. Li Wei A, Benjamin KW K, Kwai Peng C, Chua LT, James L, Goh KT, et al: Epidemiology and Control of Hand,Foot and Mouth Disease in Singapore, 2001-2007. Ann Acad Med Singapore 2009, 38(2):106-112.

8. Schuffenecker I, Mirand A, Antona D, Henquell C, Chomel JJ, et al: Epidemiology of human enterovirus 71 infections in France, 2000-2009. J Clin Virol 2011, 50(1):50-56.

9. McMinn P, Stratov I, Nagarajan L, Davis S: Neurological manifestations of enterovirus 71 infection in children during an outbreak of hand, foot, and mouth disease in Western Australia. Clin Infect Dis 2001, 32(2):236-242.

10. Chan LG, Parashar UD, Lye MS, Ong FG, Zaki SR, et al: Deaths of children during an outbreak of hand, foot, and mouth disease in sarawak, malaysia: clinical and pathological characteristics of the disease. For the Outbreak Study Group. Clin Infect Dis 2000, 31(3):678-683.

11. Komatsu H, Shimizu Y, Takeuchi Y, Ishiko H, Takada H, et al: Outbreak of severe neurologic involvement associated with enterovirus 71 infection. Pediatr Neuro 1999, 20(1):17-23.

12. Zheng ZM, He PJ, Caueffield D, Neumann M, Specter S, et al: Enterovirus 71 isolated from China is serologically similar to the prototype $\mathrm{E} 71 \mathrm{BrCr}$ strain but differs in the 5'-noncoding region. J Med Virol 1995, 47(2):161-167.

13. Chang SC, Li WC, Chen GW, Tsao KC, Huang CG, et al: Genetic characterization of enterovirus 71 isolated from patients with severe disease by comparative analysis of complete genomes. J Med Virol 2012 84(6):931-939.

14. Melchers WJ, Hoenderop JG, Bruins Slot HJ, Pleij CW, Pilipenko EV, et al: Kissing of the two predominant hairpin loops in the coxsackie B virus $3^{\prime}$ untranslated region is the essential structural feature of the origin of replication required for negative-strand RNA synthesis. J Virol 1997, 71(1):686-696.

15. Wimmer E, Hellen CU, Cao X, et al: Genetics of poliovirus. Annu Rev Genet 1993, 27:353-436

16. Bedard KM, Semler BL: Regulation of picornavirus gene expression. Microbes Infect 2004, 6(7):702-713.

17. Pelletier J, Kaplan G, Racaniello VR, Sonenberg N: Cap-independent translation of poliovirus mRNA is conferred by sequence elements within the 5'noncoding region. Mol Cell Biol 1988, 8(3):1103-1112.

18. Liu XL, Wang ZG, Yang TT, Yi T: Molecular epidemiology of human enterovirus 71 strains in Qingdao region, Shandong province, 2007-2009. Chin J Epidemio/ 2011, 32(4):382-384.

19. Evans DM, Dunn G, Minor PD, Schild GC, Cann AJ, et al: Increased neurovirulence associated with a single nucleotide change in a noncoding region of the Sabin type 3 poliovaccine genome[J]. Nature 1985, 314(6011):548-550

20. Guillot S, Otelea D, Delpeyroux F, Crainic R: Point mutations involved in the attenuation/neurovirulence alternation in type 1 and 2 oral polio vaccine strains detected by site-specific polymerase chain reaction. Vaccine 1994, 12(6):503-507.

21. Rezapkin GV, Fan L, Asher DM, Fibi MR, Dragunsky EM, et al: Mutations in Sabin 2 strain of poliovirus and stability of attenuation phenotype. Virology 1999, 258(1):152-160.

22. Arita M, Shimizu H, Nagata N, Ami $Y$, Suzaki $Y$, et al: Temperature-sensitive mutants of enterovirus 71 show attenuation in cynomolgus monkeys. J Gen Virol 2005, 86(5):1391-1401.

23. Li R, Zou Q, Chen L, Zhang H, Wang Y: Molecular Analysis of Virulent Determinants of Enterovirus 71. PLoS One 2011, 6(10):e26237.
24. Lin JY, Chen TC, Weng KF, Chang SC, Chen LL, et al: Viral and host proteins involved in picornavirus life cycle. J Biomed Sci 2009, 16(1):103.

25. Foo DG, Alonso S, Phoon MC, Ramachandran NP, Chow VT, et al: Identification of neutralizing linear epitopes from the VP1 capsid protein of Enterovirus 71 using synthetic peptides. Virus Res 2007, 125(9):61-68.

26. Guidelines for the prevention and treatment of HFMD. http://www.moh.gov. cn/publicfiles/business/cmsresources/wsb/cmsrsdocument/doc4510.doc.

doi:10.1186/1743-422X-10-115

Cite this article as: Wen et al:: Complete genome sequencing and analysis of six enterovirus 71 strains with different clinical phenotypes. Virology Journal 2013 10:115.

\section{Submit your next manuscript to BioMed Central and take full advantage of:}

- Convenient online submission

- Thorough peer review

- No space constraints or color figure charges

- Immediate publication on acceptance

- Inclusion in PubMed, CAS, Scopus and Google Scholar

- Research which is freely available for redistribution

Submit your manuscript at www.biomedcentral.com/submit
C BioMed Central 